duration 7.91 years [SD 8.314]. Total fingernail mNAPSI 75 was achieved by $0.5 \%$ PBO vs $61.5 \%$ ADA of pts with PsA and $4.6 \%$ PBO vs $40.9 \%$ ADA without PsA $(p<0.001$ for both groups). PGA-F 0 or 1 with $\geq 2$-grade reduction was achieved by $4.4 \% \mathrm{PBO}$ vs $59.3 \% \mathrm{ADA}$ with $\mathrm{PsA}$ and $7.9 \% \mathrm{PBO}$ vs $44.9 \%$ ADA without PsA $(p<0.001$ for both groups). Adverse events (AEs) in Period $A$ were reported by $55.6 \%$ PBO vs $56.9 \%$ ADA (with PsA: $56.3 \%$ PBO vs $56.7 \%$ ADA; without PsA: $55.3 \% \mathrm{PBO}$ vs $57.0 \%$ ADA without PsA); serious AEs by $4.6 \% \mathrm{PBO}$ vs $7.3 \% \mathrm{ADA}$ (with PsA: $9.4 \%$ PBO vs $10.0 \%$ ADA; without PsA: $2.6 \%$ PBO vs $6.3 \%$ ADA). Conclusions: The primary results demonstrated that in this population, ADA was more effective than PBO for the treatment of fingernail Ps, and significantly improved signs and symptoms, both overall and regardless of the presence or abscense of PsA; no new safety risks were identified with ADA eow treatment for 26 wks.

Acknowledgements: AbbVie Inc. funded this study and participated in the study design; study research; collection, analysis and interpretation of data; and writing, reviewing and approving of this publication. All authors had access to the data, and participated in the development, review, and approval, and in the decision to submit this publication.

The authors would like to acknowledge Yihua Gu for statistical support, and Jody Bennett, for medical writing support in the production of this abstract; both are employed by AbbVie.

Disclosure of Interest: B. E. Elewski Grant/research support from: Abbvie, Amgen, Boehringer Ingelheim, Celgene, Incyte, Lilly, Merck, Novan, Novartis, Pfizer, Valeant, and Viamet, Consultant for: Anacor, Celgene, Lilly, Novartis, Pfizer, and Valeant, P. A. Rich Grant/research support from: AbbVie, Allergan, Amgen, Anacor, Cassiopea, Dusa, Eli Lilly, Galderma, Janssen, Leo, Meiji, Merck, Novartis, Pfizer, Psolar, Ranbaxy,Sandoz, and Viamet, Consultant for: AbbVie, Eli Lilly, Novartis, Sandoz, Polichem and Valeant, F. Behrens Grant/research support from: AbbVie, Amgen, Celgene, Janssen, Lilly, Novartis, Pfizer, Sandoz, and Sanofi, Consultant for: Abbvie, Chugai, Celgene, Genzyme, Lilly, Novartis, Pfizer, Roche, and Sanofi, G. Guillet Grant/research support from: AbbVie, Z. Geng Shareholder of: AbbVie, Employee of: AbbVie, O. Reyes Servin Shareholder of: AbbVie, Employee of: AbbVie

DOI: 10.1136/annrheumdis-2017-eular.2148

\section{AB0757 IMPACT OF DISEASE ACTIVITY ON PHYSICAL FUNCTION AND HEALTH-RELATED QUALITY OF LIFE IN PATIENTS WITH PSORIATIC ARTHRITIS}

K. Nas ${ }^{1}$, G. Kilic ${ }^{2}$, R. Cevik ${ }^{3}$, A.Z. Dagli ${ }^{3}$, E. Kilic ${ }^{4}$, S. Sag ${ }^{1}$, U. Erkorkmaz ${ }^{5}$, A. Kamanli ${ }^{1}$, I. Tekeoglu ${ }^{1} .{ }^{1}$ Division of Rheumatology and Immunology, Department of Physical Medicine and Rehabilitation, Sakarya University Faculty of Medicine, Sakarya; ${ }^{2}$ Physical Medicine and Rehabilitation, Afyon Kocatepe University Faculty of Medicine, Afyon; ${ }^{3}$ Division of Rheumatology, Department of Physical Medicine and Rehabilitation, Dicle University Faculty of Medicine, Diyarbakir; ${ }^{4}$ Rheumatology Clinic, Afyonkarahisar State Hospital, Afyon; ${ }^{5}$ Department of Biostatistic, Sakarya University Faculty of Medicine, Sakarya, Turkey

Background: Psoriatic arthritis (PsA) is a chronic progressive inflammatory disease characterized by peripheral arthritis, dactylitis, axial joint involvement and extraarticular features. Disease consequences such as chronic pain, severe joint damage and fatigue may adversely effect on a patient's physical function and health-related quality of life $(\mathrm{QoL})$ to perform daily activities.

Objectives: The aim of this study was to investigate the potential relationship between physical function and health-related QoL and disease activity measures in patients with PsA.

Methods: For all participating patients, quality of life, functional and disease activity measures were measured by different ways: Nottingham Health Profile (NHP), psoriatic arthritis quality of life (PsAQoL), Ankylosing Spondylitis Quality of Life (ASQoL), SF36 health survey, Health Assessment Questionnaire (HAQ), BASFI, VAS pain, DAS28, BASDAI and acute phase markers including ESR and CRP.Patients with PSA were discriminated into low and high disease activity according to BASDAI ( $\geq 6$ vs $\leq 4$ ).

Results: A total of 186 patients with PsA (116 female, 70 male, mean age $43,9 \pm 12,6)$ who met CASPAR criteria were included. Their mean symptom duration was $7.9 \pm 9.1$ years. Patients with higher BASDAl score $(\geq 6)$ had significantly higher scores on all important items including health related QoL, fatigue, pain, and functional status. Correlation coefficients between disease activity and various health related QoL measurements were given in Table1. SF36 physical component score was significantly correlated with VAS-pain, BASDAI and DAS28 compared to SF36 mental component. Also, physical activity subscore of NHP was found higher correlated with disease activity indices for PsA in all NHP sections. Other quality of life measurements including PsQoL, HAQ and ASQoL were also significantly correlated with disease activity measurements.

Conclusions: Psoriatic arthritis has a major impact on patients' lives. Variable disease activity measurements were found correlated with all important QoL measurementss including NHP, SF36, PsQoL, HAQ and ASQoL. In patients with PsA, high disease activity may lead to severe impairments in daily activities and influence on participation in society.

Disclosure of Interest: None declared

DOI: 10.1136/annrheumdis-2017-eular.6639

\section{AB0758 AUDIT ON USTEKINUMAB DRUG SURVIVAL IN A DISTRICT GENERAL HOSPITAL VERSUS PSUMMIT 1 TRIAL RESULTS}

\section{G. Tracey, S. Webber. Rheumatology, Weston General, Bristol, United Kingdom}

Background: Psoriatic arthritis (PsA) is an immune mediated inflammatory disorder that affects $10-30 \%$ of patients with psoriasis. Ustekinumab, a monoclonal anti-IL-12/23p40 antibody, is approved for the treatment of PsA and plaque psoriasis ${ }^{1}$ PSUMMIT 1 was one of two phase 3 trials of ustekinumab in adults with active $\mathrm{PsA}^{2} \mathrm{In}$ England, use of medication is subject to guidance from National Institute for Health and Care Excellence (NICE). [TA340] recommend that Ustekinumab is a possible treatment, alone or with methotrexate, for adults with active psoriatic arthritis when treatment with non-biological disease-modifying antirheumatic drugs has not worked well enough if: treatment with tumour necrosis factor (TNF) alpha inhibitors is not suitable for them, or the person has had a TNF alpha inhibitor before ${ }^{3}$ We audited the survival data from our cohort of patients in district general hospital (DGH) against data from PSUMMIT trial.

Objectives: Our objectives were to evaluate drug survival of Ustekinumab in PsA, to compare real world data with that from PSUMMIT trial.

Methods: Our biologics database was searched for patients currently receiving Ustekinumab treatment for Psoriatic Arthritis and those who have had treatment failures. Length of treatment was recorded and any adverse effects which caused the treatment to be stopped. Analysis of treatment non-responders was performed including previous biologics/drug use. We then compared our results to those in the treatment arms (Ustekinumab $45 \mathrm{mg}$ or $90 \mathrm{mg}$ ) of the PSUMMIT trial at week 24 and 52.

Results:

Table 1

\begin{tabular}{lcc} 
& Ustekinumab 45mg & Ustekinumab 90mg \\
\hline DGH $(\mathrm{n}=20)$ & 15 & 5 \\
PSUMMIT $(\mathrm{n}=409)$ & 205 & 204
\end{tabular}

$\begin{array}{lll}\text { PSUMMIT }(\mathrm{n}=409) & 205 & 204\end{array}$

Table 2

\begin{tabular}{lccccc}
\hline & \multicolumn{2}{c}{ DGH } & & \multicolumn{2}{c}{ PSUMMIT } \\
\cline { 2 - 3 } \cline { 5 - 6 } & (Ust 45mg) & (Ust 90mg) & & (Ust 45mg) & (Ust 90mg) \\
\hline Week 24 withdrawal & $4 / 15$ & $0 / 5$ & & $8 / 205$ & $7 / 204$ \\
Reasons: & & & & & 3 \\
$\quad$ Adverse effects & 3 & & & 4 & 3 \\
$\quad$ Inefficacy & 1 & & & 4 & 3 \\
$\quad$ Other (consent, lost follow up) & & & & $17 / 197$ & $15 / 197$ \\
Week 52 withdrawal & $0 / 8$ & $0 / 3$ & & & \\
Reasons: & & & & 2 & 5 \\
$\quad$ Adverse effects & & & & 7 & 3 \\
$\quad$ Inefficacy & & & & 8 & 7 \\
$\quad$ Other (consent, lost follow up) & & &
\end{tabular}

Treatment Failure group (DGH): All patients had had at least one anti-TNF agent prior to Ustekinumab therapy. One patient had trialled 3 , two had two, one had one. They had been stopped either due to inefficacy or intolerance.

Conclusions: Ustekinumab has been shown to be a generally well tolerated drug. Our treatment group had proportionally more treatment failures than the PSUMMIT trial (4/20 $20 \%$ vs $24 / 4095.8 \%$ ). There is the obvious criticism that our patient numbers are very small. For eligibility in PSUMMIT trial the patients had to be anti-TNF naïve. In NHS ENgland, Ustekinumab is not NICE approved as a first line agent except in certain circumstances. Therefore, our patients have had

Abstract AB0757 - Table 1. Correlation coefficients between disease activity and various health related QoL measurements in patients with PsA [r (p)]

\begin{tabular}{|c|c|c|c|c|c|}
\hline & VAS - pain & DAS 28 & BASDAI & ESR & CRP \\
\hline NHP-pain & $0.571(<0.001)$ & $0.326(<0.001)$ & $0.644(<0.001)$ & $0.250(\mathbf{0 . 0 0 3})$ & $0.187(0.027)$ \\
\hline NHP-physical activity & $0.599(<0.001)$ & $0.335(<0.001)$ & $0.652(<0.001)$ & $0.277(<0.001)$ & $0.111(0.191)$ \\
\hline NHP-fatigue & $0.425(<0.001)$ & $0.324(<0.001)$ & $0.530(<0.001)$ & $0.287(<0.001)$ & $0.082(0.337)$ \\
\hline NHP-sleep & $0.236(\mathbf{0 . 0 0 3})$ & $0.118(0.162)$ & $0.308(<0.001)$ & $0.113(0.181)$ & $-0.026(0.764)$ \\
\hline NHP-social isolation & $0.214(0.008)$ & $0.299(<0.001)$ & $0.272(<0.001)$ & $0.080(0.345)$ & $-0.019(0.824)$ \\
\hline NHP-emotional reaction & $0.315(<0.001)$ & $0.281(<0.001)$ & $0.326(<0.001)$ & $0.085(0.315)$ & $-0.023(0.790)$ \\
\hline SF36 physical component & $-0.581(<0.001)$ & $-0.333(\mathbf{0 . 0 0 5 )}$ & $-0.449(<0.001)$ & $-0.346(\mathbf{0 . 0 0 4})$ & $-0.336(\mathbf{0 . 0 0 5 )}$ \\
\hline SF36 mental component & $-0.439(<0.001)$ & $-0.232(0.057)$ & $-0.366(<0.001)$ & $-0.250(\mathbf{0 . 0 3 8})$ & $-0.198(0.102)$ \\
\hline PsAQoL & $0.451(<0.001)$ & $0.285(<0.001)$ & $0.484(<0.001)$ & 0.103.(0.223) & $-0.005(0.955)$ \\
\hline $\mathrm{HAQ}$ & $0.428(<0.001)$ & $0.294(<0.001)$ & $0.386(<0.001)$ & $0.097(0.246)$ & $0.134(0.107)$ \\
\hline ASQoL & $0.459(<0.001)$ & $0.459(<0.001)$ & $0.489(<0.001)$ & $0.220(0.081)$ & $0.068(0.593)$ \\
\hline
\end{tabular}

